Revista de Filosofía

Volumen 66, (2010) 63 - 77

\title{
LA DIALÉCTICA PLATÓNICA COMO MODELO DE LA EXPERIENCIA HERMENÉUTICA EN LA FILOSOFÍA DE GADAMER
}

\author{
José Antonio Giménez \\ Universidad de Los Andes \\ jagimenezs@gmail.com
}

\begin{abstract}
Resumen
La interpretación evolutiva y unitaria que hace Gadamer de los escritos de Platón supone en sus fundamentos una comprensión bastante particular sobre la 'estructura pregunta-respuesta' característica de los diálogos platónicos. Este trabajo intenta mostrar la radicalidad del planteamiento gadamereano de la dialéctica platónica, así como la conexión esencial entre esta estructura y el fenómeno central de la hermenéutica, a saber, el fenómeno de la comprensión. De esta manera, ambos elementos se presentarán bajo una mutua dependencia, en cuanto que la filosofía hermenéutica se reconoce reflexivamente a sí misma en la ejecución del diálogo platónico.
\end{abstract}

Palabras Clave: hermenéutica, comprensión, experiencia, diálogo, estructura pregunta-respuesta, autoconciencia.

\section{Abstract}

Gadamer's evolutionary and unitary interpretation of Plato's writings assumes a rather particular understanding of the 'question-and-answer form' (characteristic of Plato's dialogues). This work intends to show the radicalism of Gadamer's views about the Platonic dialectic, as well as the essential connection between that structure and the central phenomenon of hermeneutics, i.e. the phenomenon of comprehending (Verstehen). In this way, both elements are shown to depend on each other, as Hermeneutic philosophy recognizes itself through the realization of the Platonic dialogue.

Keywords: hermeneutics, understanding, experience, dialogue, question and answer form, self-awareness.

\section{Introducción}

$\overline{\mathrm{RA}}$ Dentro de las diversas lecturas contemporáneas de la obra de Platón, no puede pasarse por alto la interpretación que hace el filósofo alemán HansGeorg Gadamer, quien dedicó gran parte de su carrera académica a reflexionar sobre el diálogo platónico, visualizando en este un conjunto de características especialmente apropiadas para exponer, a través de su reflexión y comentario, la aplicabilidad 
interpretativa de su filosofía hermenéutica ${ }^{1}$. Sin embargo, el interés de Gadamer por la obra del filósofo griego sobrepasa con mucho el nivel del comentario aclaratorio propio de las interpretaciones tradicionales, en la medida en que el pensamiento de Platón es concebido por él como "modelo" (Vorbild) de su misma "filosofía hermenéutica" (hermeneutische Philosophie), razón por la cual no es del todo posible separar en la obra de Gadamer su interpretación propiamente platónica de su filosofía característicamente hermenéutica ${ }^{2}$, así como no tiene sentido alguno en el espíritu de la hermenéutica filosófica hacer una distinción taxativa entre la labor interpretativa y la estrictamente filosófica. De este modo, se nos hace patente la importancia de la interpretación gadamereana del diálogo platónico, puesto que en esta interpretación se ponen en juego paradigmáticamente los principios fundamentales de la hermenéutica como 'visión de mundo' que considera que la manifestación de la verdad de las cosas tiene lugar precisamente ahí donde la apropiación de la alteridad de lo otro se vuelve posible por medio de la anticipación de las preguntas, motivaciones e intereses que pone el mismo intérprete para dar con la totalidad de sentido del objeto que se le presenta a la comprensión. De esta manera, el pensamiento de Platón puede ser entendido desde la misma filosofía de Gadamer, mientras que el pensamiento del alemán se revela en su particularidad a partir de la comprensión del diálogo platónico al que ha dado lugar la proyección antecedente.

El objetivo de este trabajo consistirá precisamente en presentar de modo convincente la conexión interna que existe entre el fenómeno de la comprensión característico de la experiencia hermenéutica y la estructura lógica que sustenta la dialéctica platónica. En este sentido, no se intentará dar razón del detalle de la interpretación de la obra platónica que nos propone Gadamer, sino simplemente me concentraré en identificar la estructura dialógica como presupuesto básico de la diversidad de tratamientos que realiza Gadamer a partir de su lectura de la obra de Platón. Trataré de responder a dos cuestiones que se encuentran internamente relacionadas entre sí: por una parte, a la validez de la interpretación del pensamiento platónico a partir de la consideración de su estructura dialógica como condición de posibilidad para un acceso adecuado a la obra del filósofo y, por otra parte, a la dependencia del pensamiento de Gadamer con respecto a esta interpretación, en la medida en que da razón de la intuición fundamental de su filosofía hermenéutica, al entregarle el modelo fundamental que debe seguir el intérprete si quiere dejar hablar al texto en su alteridad.

Dando un primer vistazo a la filosofía de Gadamer y sin entrar todavía en el detalle de su teoría hermenéutica, podemos observar que el filósofo se niega rotundamente al establecimiento de una "terminología conceptual fija", en la medida en que considera que los términos filosóficos se fundan como tales en el carácter histórico

1 Es cuantiosa la literatura de Gadamer a lo largo de su carrera académica acerca de las obras platónicas. La recolección de estos estudios puede encontrarse en H. G. Gadamer, $G W$, Bd. 5-7.

2 Para esto, véase Gadamer, WM I, pp. 368-375 y Gadamer (1965), pp. 420-424. 
del "lenguaje" (Sprache), el cual tiene lugar en sentido propio en la facticidad de la "conversación" (Gespräch). Si profundizamos en el dinamismo característico de la conversación como 'el habla del mundo de la vida', reconoceremos la presencia de un doble movimiento que avanza por una parte "de la palabra al concepto" (vom Wort zum Begriff) y por otra "del concepto a la palabra" (vom Begriff zum Wort). Considerando este constante "encontrarse en camino hacia el concepto" (Sich-auf-dem-Wege-zumBegriff-Befinden $)^{3}$ y su consiguiente vuelta a la palabra cotidiana, Gadamer justifica su consideración de la filosofía como una "historia del concepto" (Begriffsgeschichte) (Gadamer 1970), esto es, como una tarea continua e interminable de "comprensión" (Verständnis) de las palabras desde el horizonte histórico en el cual el ser humano se halla situado, dejando a un lado el ideal metodológico de la ciencia y la filosofía modernas, que pretenden constituir un lenguaje absolutamente unívoco y sistemático desarraigando a las palabras de su origen histórico y cotidiano.

Según las palabras del mismo Gadamer, "el modelo imperdible de este arte de romper los conceptos que se vuelven fijos, es el diálogo platónico y la dirección de la conversación del Sócrates platónico" (Gadamer 1970, p. 90). Gadamer considera que todos los diálogos platónicos deben ser interpretados como conversaciones dependientes tanto de la situación concreta del "mundo de la vida" en medio del cual se despliega la conversación, como de la aprobación continua del "interlocutor" (Gesprächspartner) que se ve comprometido en el desarrollo del diálogo, en la medida en que las preguntas que se le dirigen lo interpelan en su propio modo de $\operatorname{ser}^{4}$. Este principio, aunque se da de modo cabal en los diálogos tempranos, no es nunca dejado de lado según Gadamer ni en los diálogos medios ni en los tardíos. En el caso de la obra madura de Platón, aunque nos encontremos ya con un 'Sócrates' que no se comporta como "el que nada sabe" (Nichtwissender), sino como "uno que sí sabe" (Wissender), no dejamos de encontrarnos sin embargo con la actitud socrática fundamental del "hacer preguntas" (Fragender), cultivando todavía de esta manera "el saber que Platón denominó 'Dialéctica', como el arte de saber llevar una conversación" (Gadamer 1985, p. 107). Finalmente, sería una reducción equivocada según Gadamer considerar que el método de la "división de conceptos" (diáiresis) propio de los diálogos tardíos constituye únicamente "una etapa histórica de un desarrollo que conduce la dialéctica y el método dialógico a ser superados en la epistéme aristotélica" (Gadamer 1931, p. 14), a pesar de que sea evidente su conexión con el "método demostrativo" de Aristóteles (apódeixis). La diáiresis "reproduce el mismo proceder de la conversación que paso a paso avanza de un acuerdo a otro" (Gadamer 1991, p. 340), siguiendo por

3 Fernández-Arancibia formula esta expresión como corolario de la concepción de Gadamer del diálogo como un "encontrarse en camino hacia la idea" (Sich-auf-dem-Wege-zurIdee-Begriff-Befinden). Para esto, véase Fernández-Arancibia (2007), pp. 8 ss.

$4 \quad$ Para esto, véase Gadamer (1972). Para un interesante análisis sobre la importancia de los aspectos literarios y dramáticos para el desarrollo y desenlace de las cuestiones filosóficas en Platón, véase Boeri (2007). 
tanto a la dialéctica platónica en su necesidad interna de aprobación dialógica de la pregunta que ha sido planteada ${ }^{5}$.

En esta misma línea, Gadamer considera que las ideas o formas platónicas deben entenderse desde el diálogo como el trasfondo que actúa como su "condición de posibilidad". De esta manera, la idea como tal no se tendrá que comprender como la "meta" (Ziel) a la cual tiende el diálogo en vistas a su realización, sino más bien como el "punto de partida" (Anfang) que da lugar al desenvolvimiento de la conversación, esto es, como la 'pregunta' (Frage) que abre el horizonte de la verdad. Asimismo, la arquetípica 'Idea del Bien' se hará presente en la continuidad de "la pregunta por lo Bueno" a lo largo de los diálogos platónicos, cumpliendo un rol fundamental como la pregunta que se preocupa por la rectitud de la propia existencia. En este sentido, "el dar razón de lo que se dice" (lógon didónai) solicitado por Sócrates continuamente a sus interlocutores ${ }^{7}$, debe comprenderse como una exigencia respecto a la coherencia entre lo sostenido por el hablante y su vida misma, "en cuanto que este exponerse a sí mismo significa precisamente hacerse cargo de esta pregunta" (Fernández-Arancibia 2007, p. 7), revelándose en consecuencia la 'pregunta por lo bueno' como la pregunta conductora de todos los diálogos.

La interpretación unitaria de la obra platónica que intenta modelar Gadamer se basa en la continuidad de ciertas características fundamentales del método dialéctico que se presentarían indistintamente a lo largo de todos los diálogos del filósofo. Estas características que justifican la visión gadamereana de la obra de Platón como un "encontrarse en camino hacia el concepto" y no como un conjunto de proposiciones ordenadas dentro de un sistema que pretende dar razón acabada de la totalidad de las cosas existentes, deben comprenderse a partir de un análisis exhaustivo de la estructura del mismo método dialógico como un 'formato de preguntas y respuestas'. La presencia de tal 'estructura pregunta-respuesta' es la constitución fundamental en la cual debemos hallar el carácter peculiar que hace del diálogo platónico un principio filosófico que es capaz de sostener la unidad de la obra platónica.

En lo que sigue, para mostrar el carácter fundamental de la estructura dialógica para el pensamiento de Gadamer i) comenzaré por referirme a los antecedentes inmediatos de la filosofía hermenéutica de Gadamer, con la intención de poder dar consiguientemente razón de la 'experiencia de la comprensión' como el modo de acceso originario al mundo; ii) luego, me preocuparé por esclarecer el lugar fundamental que ocupa la 'estructura pregunta-respuesta' como estructura lógica propia del fenómeno de la comprensión y la importancia del modelo de la dialéctica platónica para dar razón

5 Para la interpretación de la diáresis en continuidad con la dialéctica platónica, véase Gadamer (1978), pp. 128-227.

6 Para la concepción de las ideas como condiciones de posibilidad del diálogo, véase como antecedente Natorp (1921). Para un desarrollo interesante de esta tesis entre los discípulos de Gadamer, véase Wieland (1982), pp. 150 ss.

$7 \quad$ Véase, por ejemplo, Platón, Teeteto 169a7; Fedón 76b8; 101d6; y Cármides $175 b 3$. 
de la tarea del intérprete en su ejercicio de comprensión de textos; iii) finalmente, intentaré hacerme cargo de los alcances y las limitaciones fundamentales que cabe establecer como resultado de la exposición hecha.

\section{La experiencia de la comprensión en Gadamer}

Gadamer visualiza en la 'estructura pregunta-respuesta' propia de la argumentación de la filosofía platónica una estructura fundamental de la 'experiencia de la comprensión'. Para hacernos cargo de esta cuestión será necesario repasar antes algunos puntos centrales de la filosofía hermenéutica de Gadamer, conectando su pensamiento con la tradición inmediata que lo antecede y que le prepara el camino para la formulación de su propia filosofía. Sin embargo, antes de referirme a la cuestión propiamente hermenéutica, intentaré hacerme cargo de la visión aristotélica del fenómeno de la 'experiencia', fenómeno que se encontrará en el núcleo de la tradición pre-gadamereana y que cumplirá una función fundamental en la solución propuesta por Gadamer al fenómeno de la comprensión.

El concepto de 'experiencia' ha estado sujeto a una compleja variación a lo largo de la historia de la filosofía. Gadamer intenta reconsiderar este concepto desde su concepción aristotélica originaria como el proceso por medio del cual el conjunto de las percepciones particulares conforman por su constante repetición una 'cierta unidad significativa' dentro del alma del sujeto (Aristóteles, Segundos Analíticos II, 19). La "experiencia" (empeiría) se da en esta articulación del particular percibido en el presente con el conjunto de los particulares de clase similar, sin llegar sin embargo a la visión objetiva de la totalidad percibida: la empeiría (Erfahrung) radica únicamente en el acto por el cual lo pasado es "guardado" (Behalten), en la medida en que somos capaces de "reconocerlo" (Wiedererkennen) en el presente como 'lo mismo' (Gadamer 1931, p. 19). El "arte" (téjne), en cambio, implica ya el conocimiento de las "causas" (arjai) que subyacen a la multiplicidad de las percepciones ${ }^{8}$ : en este sentido, experiencia y téchne no se distinguen en cuanto a su modo de "producción" (Verrichtung), sino en cuanto a su "disponer" (Verfügen) de la ejecución, en la medida en que la primera se acredita únicamente por medio del éxito o resultado de cada producción concreta, mientras que la segunda se asegura del "reproducir" (Herstellen) obtenido como 'disposición general', anticipándose con seguridad a toda posible 'producción'. De este modo, Aristóteles considera la experiencia como un cierto modo de conocimiento

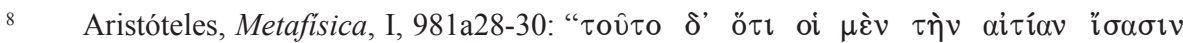

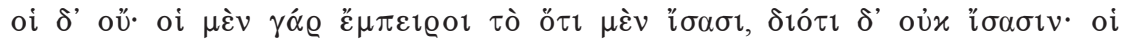

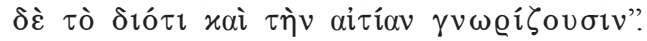

9 Gadamer 1931, pp. 19-20. En este sentido, podemos decir que la 'experiencia' no dispone en absoluto de la producción, puesto que siempre está abierta al futuro, esto es, a la posibilidad latente de que se frustre la producción proyectada a partir de los resultados 
destinado a ser superado por la téjne y por el saber científico-teórico, en la medida en que la concibe como un conocimiento inseguro que hace las veces de mediador entre la percepción sensible y la "conformación del concepto" (Begriffsbildung) (Gadamer, WM I, p. 358).

La enunciación y consiguiente devaluación del concepto de experiencia por parte de Aristóteles, es para Gadamer una consecuencia necesaria de considerar la esencia de la experiencia "por referencia a la ciencia" (im Blick auf die 'Wissenschaft') y no desde sí misma. Este modo de consideración de la experiencia ha dominado la historia de la filosofía occidental, siendo puesta en cuestión recién en el siglo XX con el conocido "giro hermenéutico" (hermeneutische Wendung) de Martin Heidegger. Frente a la fenomenología eidética de Husserl, Heidegger opondrá una fenomenología de tipo hermenéutico, observando que es el "comprender" (Verstehen) -y no la idealidad de la conciencia- el modo originario de operar de la existencia histórica como "ser-en-el-mundo" (Sein-in-der-Welt), constituyendo como tal el "movimiento básico de la existencia humana" (Gadamer 1968, p. 103). Según la analítica existencial que realiza Heidegger en Ser y Tiempo, en la "comprensión" radica la posibilidad de que la existencia histórica trascienda el ser como "presencia" (Vorhandenheit), puesto que la comprensión opera en la temporalidad como "proyección" (Entwurf) y "anticipación".

En la medida en que el verbo 'comprender' no logra traducir completamente la amplitud semántica de la palabra alemana, se vuelve necesario hacer la distinción entre el comprender "reproductivo" y el "productivo"10. Verstehen hace referencia por una parte, en su uso transitivo como etwas verstehen ("comprender algo"), a la apropiación de unidades de sentido ya constituidas: en este caso, se habla de una comprensión reproductiva, en la medida en que no se participa de la constitución de lo comprendido, sino que únicamente lo hacemos aparecer. Por otra parte, el verbo alemán hace referencia en su uso reflexivo como sich auf etwas verstehen ("entender de algo, entenderse con algo") a la acción por la cual el sujeto se proyecta a sí mismo en el objeto de comprensión, de modo que participa de su configuración, abriéndosele a su vez nuevas posibilidades de constitución de sentido: tal es la comprensión productiva, siendo este precisamente el sentido fundamental en que Heidegger utiliza la palabra Verstehen. Ahora bien, en la medida en que la comprensión es un proyectarse en las cosas, "todo comprender es en último término un comprenderse", dado que el proyectarse de sí mismo es a la vez un abrir nuevas posibilidades para sí (Gadamer, WMI, pp. 264-265). Así, queda de manifiesto el carácter fundamental de la 'comprensión' para la existencia, en cuanto que posibilita el desenvolvimiento de la temporalidad e historicidad del estar ahí de la existencia (Heidegger, SZ, pp. 31-33).

anteriores, en la medida en que la 'ejecución misma' es la que dictará el fortalecimiento o debilitamiento de la experiencia como modo de conocimiento.

10 Heidegger, SZ, p. 31. Para una aclaratoria presentación del doble sentido de la palabra Verstehen en la lengua alemana, véase Vigo 2005, p. 259. 
Gadamer recoge el planteamiento hermenéutico de Heidegger y lo desarrolla en un sentido particular. Para el filósofo, la hermenéutica consiste en la conciencia metódica y reflexiva que hace posible la comparecencia de la verdad, de modo que su proyecto se identifica con el proyecto universal de la filosofía. Sin embargo, esta tarea de la filosofía hermenéutica no tiene nada que ver con la pretensión de objetividad absoluta de la filosofía moderna: más bien se trata de "asegurarse en las cosas mismas" haciéndose cargo de las propias expectativas. Por consiguiente, los propios "prejuicios" (Vorurteile), proyectados en la comprensión a modo de anticipaciones, son necesarios para que lo otro se manifieste en su verdad: la tarea hermenéutica no consiste por lo tanto en anular las propias anticipaciones -proyecto de todos modos imposible bajo los presupuestos hermenéuticos-, sino en volverse consciente de estas como propias expectativas de sentido.

Ahora bien, la tarea de reflexión sobre los prejuicios no busca suspenderlos ni superarlos en una objetividad pura, sino más bien hacer de ellos enunciados cuestionables, esto es, preguntas que posibiliten la manifestación de la verdad de lo otro (Gadamer, WM I, p. 304). A este modo de concebir la reflexión histórica a partir de la estructura lógica de la pregunta, Gadamer lo llamará "principio de la historia efectual" (Prinzip der Wirkungsgeschichte). La tarea hermenéutica consiste por lo tanto en el "desplazarse a sí mismo" (Sichversetzen) al horizonte del objeto de comprensión, sin perder en este desplazamiento el propio "horizonte histórico" (historischer Horizont) y sin imponer a la vez el propio horizonte sobre el horizonte de la "tradición" (Überlieferung) que se pretende comprender. La comprensión es por tanto, en palabras del mismo Gadamer, "el proceso de fusión de estos presuntos horizontes para sí mismo" (Gadamer, WM I, p. 311). Sin embargo, esta "fusión" (Verschmelzung) no significa de ningún modo la superación de la "tensión" (Spannungsverhältnis) originaria entre el presente y el pasado, en la medida en que en la fusión de horizontes no se confunde lo propio con lo ajeno, sino que, al contrario, se destaca la diferencia en la comprensión de la alteridad.

Sin embargo, Gadamer considera que su filosofía hermenéutica no estará totalmente liberada de la 'filosofía de la reflexión' de Hegel, mientras no se delimite 'la estructura de la conciencia de la historia efectual', ya que el concepto de 'conciencia' puede ser malentendido como una prosecución del proyecto de unificación de la historia con el espíritu absoluto (Gadamer, WMI, p. 351). En este punto, Gadamer señala que 'la estructura de la conciencia de la historia efectual' debe comprenderse como "experiencia" (Erfahrung). Cabe entonces recordar la concepción gadamereana de la empeiría en la filosofía de Aristóteles, concepción a partir de la cual Gadamer pretende fijar críticamente su caracterización de la experiencia propiamente hermenéutica.

Al parecer de Gadamer, lo que sea la experiencia hay que buscarlo en su mismo proceso y no por referencia a la 'conformación del concepto', en la medida en que este presunto resultado de la experiencia no se muestra como aquello en función de lo cual esta adquiere sentido. Desde esta perspectiva, Gadamer distingue dos momentos de la 'experiencia': un primero, en el cual las experiencias se integrarían con nuestras 
expectativas, confirmándolas positivamente ${ }^{11} \mathrm{y}$, un segundo, donde las experiencias actuarían de modo negativo o destructivo en relación con nuestras expectativas, alterando nuestra conciencia anticipativa que se sostenía en la seguridad de la disposición en el futuro de las expectativas puestas en cuestión por las nuevas experiencias. Para explicar el carácter 'constructivo' de la negatividad de la experiencia, Gadamer recurrirá a la descripción hegeliana de la 'experiencia' como principio de la "dialéctica".

Aunque hablemos de experiencia como de una unidad de casos repetidos, en sentido estricto una experiencia en cuanto tal siempre es única e irrepetible, en la medida en que está sustentada en la "historicidad" (Geschichtlichkeit). El ideal de la conciencia de aprehender el mundo de modo unitario le exige reestructurarse continuamente ante la adquisición constante de nuevas experiencias: de esta manera, la conciencia "se invierte" (es kehrt sich um), esto es, se vuelve extraña a sí misma, para poder entonces 'convertir' la experiencia nueva y extraña en experiencia propia y familiar -esto es, para lograr 'reconocerse a sí mismo en lo otro' en la nueva unidad alcanzada consigo mismo. De este modo, en cuanto que la experiencia consiste en una "inversión de la conciencia" (Umkehrung des Bewusstseins), el movimiento dialéctico debe entenderse precisamente a partir de la experiencia (Gadamer, WM I, pp. 359-361). Sin embargo, el ideal hegeliano de identificación de lo extraño con la propia conciencia impide a fin de cuentas que se manifieste el carácter inagotable y la apertura infinita a nuevas posibilidades propias de la esencia histórica de la experiencia. La experiencia no tiene como finalidad la comprensión de la totalidad de las cosas, en la medida en que tal objetivo se fundamenta en una concepción de la experiencia que pone el énfasis en su positividad y no en el horizonte negativo de las posibilidades no realizadas: se trata más bien de ampliar las posibilidades en vez de reducirlas, de volverse siempre más consciente de "los límites de toda previsión" (die Grenze alles Voraussehens) y por tanto abrirse a la posibilidad de adquirir siempre nuevos horizontes de comprensión. La verdadera experiencia es la experiencia de la propia historicidad, esto es, de la finitud inherente al ser humano. En este sentido, el tercer y último momento de la experiencia es el "autoconocimiento" (Selbsterkenntnis), por el cual el hombre se reconoce a sí mismo en el fracaso de las propias expectativas ${ }^{12}$.

Este último modo de comprensión se corresponde propiamente con el modo de ser de la experiencia hermenéutica y tiene su modelo característico en la figura del diálogo y, en particular, en la figura del diálogo platónico. Queda entonces por considerar cómo se realiza este 'diálogo con la tradición', sirviéndonos de la estructura

11 De esta manera, Gadamer no rechaza sin más el carácter funcional o ‘teleológico' de la experiencia señalado por Aristóteles, como el camino hacia la formación del concepto; se trata más bien de aceptar esta caracterización como un 'momento' dentro del movimiento de conformación de la experiencia llevada a su plenitud. Para esto, véase Gadamer, WM I, pp. 355-356.

12 Gadamer, $W M I$, p. 363: "La verdadera experiencia es aquella en la que el hombre se hace consciente de su finitud". 
de la "dialéctica de Platón" y del modo en que este filósofo encara particularmente la cuestión de la comprensión de la opinión del otro.

\section{La primacía de la pregunta para la comprensión}

El 'principio de la historia efectual' que lleva a Gadamer a afirmar que la comprensión se realiza en la 'fusión de horizontes' característica de la 'conciencia hermenéutica de la historia efectual', es derivado de "la estructura de la pregunta" que posibilita la aparición de lo otro en su alteridad, en la medida en que las propias anticipaciones de sentido dejan hablar a lo otro, al ser cuestionadas en su valor de verdad. Toda experiencia está de este modo precedida de una pregunta, esto es, de un cuestionamiento de las propias posibilidades frente a lo extraño que se nos presenta. En cuanto que la pregunta cuestiona, le es inherente una cierta negatividad, y en cuanto que la pregunta está abierta a más de una respuesta, responde a la estructura de apertura de toda experiencia hermenéutica. En la medida en que el cuestionamiento sobre las propias expectativas recae a fin de cuentas en un cuestionamiento sobre la propia incapacidad de previsión y, en definitiva, del propio ser histórico, la pregunta en su radicalidad ha de comprenderse como un cuestionamiento que pone en duda la misma posibilidad de nuestro acceso al mundo y, de esta manera, la posibilidad misma de toda posible comprensión. Este cuestionamiento radical lo encontramos en la conocida conciencia socrática de la propia ignorancia, conciencia que es expresada de un modo positivo como un "saber que no se sabe" (das Wissen des Nichtwissens). La producción de este estado de conciencia tiene lugar cuando el interlocutor de Sócrates vuelve la mirada sobre sus propias expectativas y percibe la inseguridad de estas frente a las conclusiones obtenidas por medio del diálogo; tal experiencia es descrita por Platón bajo el estado de ánimo de la aporía. Tendremos que fijar por tanto la mirada en el sujeto que 'es cuestionado' en el diálogo y no en el paradigmático rol que juega el personaje 'Sócrates', en la medida en que es su interlocutor quien debe experimentar la comprensión de su propia finitud.

Sin embargo, antes de referirnos al fenómeno de comprensión que tiene lugar en el diálogo como tal, será necesario profundizar más en la esencia misma de la "pregunta" (Frage). En primer lugar, la 'pregunta' como tal contiene en sí un "sentido" (Sinn). Por esta razón, aunque no quepa hablar de una pregunta como verdadera o falsa, la pregunta sí puede ser valorada como adecuada o inadecuada, en la medida en que puede tener sentido o no tenerlo. El 'sentido' como tal es la apertura de una dirección que orienta el camino en el que se dará la respuesta, por lo cual toda respuesta se encuentra como tal latente en el sentido que tenga ya la pregunta. En la medida en que la pregunta abre un sentido, lo preguntado o lo que es puesto en cuestión por la pregunta, es "quebrantado en su ser" al introducirse una orientación que va más allá de lo propiamente enunciado. De esta manera, "el sentido del preguntar consiste 
precisamente en dejar al descubierto la cuestionabilidad de lo que se pregunta" ${ }^{13}$. Sin embargo, la "suspensión" (Schwebe) o el "rompimiento" (Aufbrechen) del carácter dogmático de lo preguntado no quiere decir en absoluto que se cierre la posibilidad de decir lo 'verdadero' sobre la cuestión misma, sino más bien, al contrario, significa que lo preguntado se abre a la posibilidad de ser por primera vez afirmado como 'verdadero'. Podemos decir que la esencia de la 'pregunta' incluye como 'sentido' un carácter de "primacía" frente a la respuesta, en la medida en que es la primera la que posibilita la venida de la segunda. El 'sujeto que pregunta' no puede guardar dentro de sí la respuesta de lo que está preguntando -como ocurre en un diálogo de tipo 'didáctico'-, en la medida en que la 'pregunta' se establece desde la conciencia del 'no saber' y bajo el deseo auténtico de llegar a saber lo que se ignora. Así podemos establecer una tercera característica de la esencia de la pregunta consistente en encontrarse siempre en dirección hacia 'la verdad'. Sin embargo, esta búsqueda de 'verdad' no consiste solo en una actitud del 'sujeto que pregunta', sino que se encuentra ya en la 'estructura misma de la pregunta', en cuanto que esta abre desde sí un 'horizonte' limitado que señala el camino hacia la respuesta. Esto quiere decir que una pregunta tiene que ser 'planteada' bajo la determinación de una disyunción entre un "así o de otro modo" (So oder So). Podemos ver ahora cómo el "saber" (Wissen) tiene lugar a partir del "preguntar" (Fragen), sin ser ya el 'preguntar mismo': conocemos la cosa cuando hemos profundizado por la pregunta en la falsedad de las instancias contrarias a la respuesta que se ha dado como verdadera, de modo que la disyunción como tal es superada en la actualización de una de las partes (Gadamer, WM I, p. 370). Por esta razón, la hermenéutica considera todo "enunciado" (Aussage) como una "respuesta" (Antwort) a una 'pregunta previa', de modo que no es posible sostener ni comprender ninguna cuestión si no se tiene presente a la vez la pregunta que motivó dicha respuesta (Gadamer 1968, p. 110).

Así debe comprenderse la distinción platónica entre "opinión” (dóxa) y "conocimiento" (epistéme), a saber, como la distinción entre el dogmatismo que reprime el preguntar al imponerse por la autoridad de la sola convicción y la apertura que "sabe pensar las posibilidades como posibilidades" ${ }^{14}$. El arte de la dialéctica como "arte del

13 Gadamer, WM I, p. 369. Aquí podemos ver cómo se articula la cuestión del 'sentido' a partir de la 'estructura pregunta-respuesta': cuando Gadamer sostiene a partir de los presupuestos básicos de la filosofía hermenéutica que el modo originario de comparecencia del 'mundo' en la 'conciencia histórica' es bajo la forma de un 'sentido' que es proyectado por el mismo sujeto, no debemos considerar que tal 'proyección' consista en una “imposición de sentido" ('Einlegen'von Sinn) - al modo en que Nietzsche concebía el acto de comprensión -, sino más bien en un "hallazgo de este" ( Finden'von Sinn) por medio de una pregunta que abre el objeto de comprensión en su esencial cuestionabilidad. Para esto, véase Gadamer 1983, pp. 339-340.

14 Gadamer, WM I, p. 371. Esta formulación es completamente coherente con el pasaje de Protágoras 313c-314b, donde 'Sócrates' precave al joven Hipócrates de recibir sin más "las enseñanzas" (tá mathémata) de Protágoras, en cuanto que los sofistas comercian con los bienes del alma como si fueran "mercancías transportables de un lugar a otro" (tá 
preguntar" (Kunst des Fragens) no se realiza en la persuasión del otro, en la medida en que la pregunta solo puede ser sostenida por quien se mantenga en lo abierto de las posibilidades: de este modo, el esfuerzo del que dirige la conversación debe estar en el "sostener" (Festhalten) la pregunta a lo largo del diálogo, impulsándola, "reiterándola" (Weiterfragen) y desplazándose siempre dentro de su horizonte (Gadamer, WM $I$, p. 372). Ahora bien, el que dirige las preguntas requiere de la correspondencia del que responde, en cuanto que la 'dirección de la conversación' no puede avanzar de otro modo que por medio de las respuestas que han sido impulsadas por las preguntas. Por esta razón, el diálogo tiene la 'estructura pregunta-respuesta', lo que implica en primer lugar que tanto el que pregunta como el que responde deben ponerse bajo la dirección del "asunto" (lógos) que está en cuestión ${ }^{15}$. Como señala Gadamer, "lo que sale en su verdad es el lógos, que no es mío ni tuyo", por lo cual las partes en diálogo deben necesariamente contener las pretensiones de sus convicciones personales para dejar que el asunto mismo se despliegue en sus posibilidades. La cuestión del diálogo es fundamentalmente una cuestión de comunidad de comprensión, esto es, del esfuerzo mutuo por "mirar la misma cosa bajo la unidad de la idea" (synorán eís hén eidos) de alcanzar el objetivo de la comprensión (Gadamer, WM I, p. 373-374). Por esta razón, el diálogo que quiere realizarse como tal no puede concebirse como una lucha de 'suma cero'16, sino como una ganancia para ambas partes del diálogo. En esto consiste precisamente el principio hermenéutico de fortalecer la opinión del otro a partir de una interpretación caritativa, de modo que pueda presentarse lo que piensa el otro en su alteridad, con lo cual las posibles debilidades de la argumentación se podrán hacer manifiestas tanto para el que pregunta como para el que es puesto en cuestión.

Sin embargo, cabría preguntarse cómo se realiza el proceso de comprensión en el sujeto de las preguntas, siendo ciertamente la pregunta y no la respuesta la que garantiza el proceso comprensivo. Es posible que esto se entienda mejor si volvemos al proceso hermenéutico por excelencia, que consiste en la interpretación de textos. A la tarea hermenéutica le corresponde ciertamente la estructura de la conversación y esto no bajo un modo de comprensión metafórico, sino precisamente como lo que

agógima) que no producen ningún efecto en la persona que las recibe. Para un análisis de este pasaje en esta línea, véase Gadamer 1953, pp. 42-43.

15 Se trata en este sentido de un "comprenderse sobre algo" (sich in etwas verstehen) y no de un 'comprender lo que se encuentra en la mente del otro'. Para esto, véase Gadamer 1957, p. 55.

16 Vigo 2001. En este excelente trabajo, Vigo intenta precisar las distintas condiciones que permiten que el diálogo pueda llevarse a buen término por medio de la "cooperación" de las dos partes en cuestión. Para ejemplificar esto, Vigo recurre principalmente a la situación confrontacional que tiene lugar en el Gorgias, donde podemos observar con claridad cómo se vuelve imposible la prosecución del diálogo cuando una o las dos partes que lo integran suben a la palestra con la proyección bivalente de 'perder o ganar'. Este tipo de "juego de suma cero" no se sostiene sino bajo una falsa concepción del diálogo (“el pseudo-diálogo”) que no supera la posibilidad del 'autoengaño'. Para esto, véase esp. pp. 14 ss. 
le corresponde en su esencia misma. La interpretación de textos es propiamente un diálogo entre dos partes que se encuentran en lo abierto de la fusión de horizontes; la lejanía del texto debe ser superada por la voluntad del intérprete de 'hacer hablar' al texto como si este se encontrara en la inmediatez del diálogo. De ahí la clásica polémica de Platón contra la falta de referencia de los textos escritos y la preeminencia del lenguaje vivo que tiene lugar en el diálogo. Sin embargo, no debe pensarse que el diálogo con el texto consista en un intento por comprender lo que el autor del texto pensaba, en la medida en que el diálogo se establece con el 'texto mismo' (Gadamer, WM I, pp. 377-379) así como en la dialéctica platónica la atención tampoco recae en la subjetividad del otro, sino que está puesta en el lógos mismo que es desenvuelto por los que dialogan ${ }^{17}$. Solo cuando nos 'aseguramos en la cosa misma' podemos hacer justicia al otro, el cual entra junto con nosotros en el horizonte del lenguaje en el que se desenvuelve el diálogo. Si no existiera como trasfondo esta participación en el elemento común del lenguaje, sería imposible que tuviera lugar la comprensión. Por esta razón, la tradición se nos da como lenguaje y podemos comprenderla solo desde nuestro horizonte lingüístico (Gadamer, WM I, pp. 375-384).

En la experiencia hermenéutica, la 'pregunta' por medio de la cual anticipamos el sentido del texto es siempre una pregunta motivada antes por 'lo que el texto nos pregunta a nosotros", de modo que el "preguntar" tiene por condición previa el "preguntarse". En esto consiste la 'conciencia de la historia efectual', a saber, en reconocer la imposibilidad de anticipar el sentido de un fenómeno histórico sin estar ya de antemano determinado por él. De este modo, vemos cómo la relación entre pregunta y respuesta queda invertida, siendo ahora el intérprete como tal quien está puesto en cuestión. Cuando revisamos ahora en esta perspectiva el carácter de la dialéctica platónica, hallamos sin dificultad el modo en que se realiza la comprensión en el diálogo. En la puesta en juego de las distintas opiniones que operan en los diferentes diálogos platónicos, observamos que el "pensar" (Denken) como tal es concebido como un "preguntarse" (Sichfragen), de modo que la finalidad del 'preguntar' solo adquiere sentido cuando el sujeto que responde 'se cuestiona a sí mismo' en la recepción comprensiva de la pregunta. En este sentido, el "comprender la cuestionabilidad de algo es siempre preguntar" (Gadamer, WM I, p. 380). Asimismo no cabe concebir al sujeto que dirige las preguntas sino como un sujeto que se está en todo momento enfrentando con las preguntas que a la vez está sosteniendo. En toda comprensión tiene lugar una "autocrítica" (Selbstkritik) (Gadamer 1968, p. 116). Los diálogos no solo reconstruyen los fenómenos comprensivos, sino a su vez los "fenómenos disfuncionales" en los cuales no se alcanza acuerdo alguno, en tanto que el contexto de uso de la palabra está perturbado por la no participación y el no cuestionamiento de cualquiera de las partes

17 En Protágoras 336c5-d2 vemos que aparece el lógos como "aquello que hay que saber

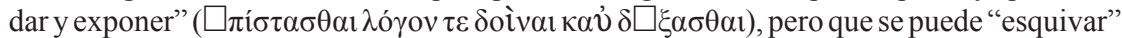

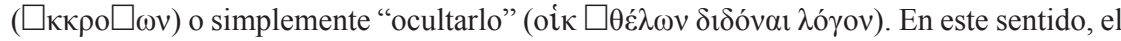
lógos está más allá de las opiniones particulares de los interlocutores, lo que no quita el hecho de que el lógos se manifiesta cuando 'se pone en juego en el diálogo'. 
en diálogo ${ }^{18}$. Esto se ve plasmado en los distintos modos de "caída del habla"19 que podemos encontrar de modo paradigmático en la representación platónica de los sofistas y los retóricos. Por consiguiente, la experiencia hermenéutica de la comprensión debe concebirse como una experiencia que ha de encontrarse actualizada a lo largo de todo el diálogo, puesto que solo así es posible desplegar las posibilidades de lo cuestionado; de este modo, cabe considerar que la "situación aporética" (aporetische Situation) como tal, aunque represente de modo peculiar el fenómeno de "conversión" y "autoconocimiento" que tiene lugar en el sujeto que es conducido a la apertura de las posibilidades por el cuestionamiento de sus propias proyecciones, no consiste en otra cosa más que en un 'fenómeno paradigmático' de la experiencia comprensiva que se sostiene a lo largo de todo el diálogo por medio del 'preguntarse'. En este sentido, aunque podamos valorar el aspecto aporético de los diálogos platónicos como un modo de realización manifiesto del fenómeno hermenéutico, la comprensión como tal debe ser reconocida como un fenómeno inherente a la estructura del diálogo en general, el cual puede terminar tanto en la homología como en la aporía. La caída en la situación aporética debe concebirse como una posibilidad siempre latente en la conversación, mas no como una condición sine qua non para la realización del fenómeno hermenéutico, el cual, en la medida en que implica un constante 'auto-cuestionamiento', reconoce la presencia de un residuo aporético que está siempre en un interminable proceso de 'auto-superación'.

\section{A modo de conclusión}

Como he intentado mostrar a lo largo de este trabajo, Gadamer reconoce en la estructura de la dialéctica característicamente platónica un sentido fundamental en cuanto que responde a la pretensión de alcanzar una "fusión" de los interlocutores por medio del acuerdo, manteniendo a la vez la "tensión" característica de la diferencia entre ambos. El modo en que Platón nos transmitió su filosofía no obedece por tanto a una mera finalidad pedagógica o literaria, guardando una relación de carácter accidental con el contenido propiamente filosófico, sino que se trata del mismo "ejercicio del pensar filosófico", el cual siempre se desplaza a partir de la situación fáctico-contextual en que tiene lugar. Tal concepción del diálogo platónico es lo que permite a Gadamer aventurar su interpretación unitaria de la obra platónica, como el camino

18 Sócrates señala en el Gorgias (487a) la existencia de tres condiciones fundamentales que debe poseer el sujeto que quiere llevar un diálogo a buen término: el "conocimiento" (epistéme), la "buena voluntad" (eúnoia) y la "honestidad en el hablar" (parresía). Estas tres aptitudes pueden ser comprendidas perfectamente dentro de la actitud hermenéutica del constante 'auto-cuestionamiento' sobre los propios límites del saber, en la medida en que dicha actitud implica una 'aperturidad' radical por parte de los interlocutores que ponen en juego las propias expectativas de sentido en el 'preguntar' y el 'responder'. Gadamer 1931, pp. 33-38 y Gadamer 1983, pp. 330-360. 
reflexivo de la "palabra hacia el concepto", esto es, como un 'diálogo' en el cual la pregunta siempre mantendrá su primacía sobre las respuestas.

Además de la validez de la interpretación del diálogo platónico realizada por Gadamer, podemos ver también, como queda dicho, que existe una clara dependencia de su pensamiento con respecto la 'estructura pregunta-respuesta' del diálogo platónico. En este sentido, se pueden señalar los siguientes alcances: i) la estructura de la pregunta se muestra primera y fundamentalmente como el modo en que tiene lugar la 'fusión de horizontes', en la medida en que la proyección de sentido que se realiza bajo la 'conciencia de la historia efectual' consiste en un poner en cuestión la seguridad de las propias expectativas, de modo de que sea posible que el objeto de la comprensión se manifieste en su alteridad; ii) la pregunta como anticipación de sentido se manifiesta de modo paradigmático en la dialéctica platónica, constituyendo a la pregunta como el principio que antecede y hace posible la realización de todo diálogo; iii) la comprensión hermenéutica no solo concibe al diálogo como un modelo comparativo, sino que guarda en sí la misma estructura del diálogo como el auténtico ideal hermenéutico; iv) el 'comprenderse' tiene lugar en el diálogo platónico como el 'preguntarse', tanto del que interroga como del que responde, de modo análogo a como el texto dirige preguntas al intérprete; v) finalmente, el modo de proceder de los diálogos hace manifiesto el fenómeno de 'conversión-inversión' que permite el autoconocimiento como realización aplicada de la experiencia de la comprensión e interpela a su vez al lector mismo, de modo que en él se realice a su vez un proceso de 'auto-comprensión'.

Si tomamos en consideración las razones dadas, podemos observar sin mayor dificultad cómo los pensamientos de filósofos tan distantes en el tiempo y en el contexto histórico - como lo son Platón y Gadamer -, pueden entrar en un productivo diálogo filosófico, que posibilita la mutua comprensión en una interpretación coherente y abierta a nuevas expectativas de sentido, donde la presencia de una de las partes del diálogo no oculta, sino que, al contrario, da lugar a la manifestación de la alteridad de la parte que se pone en juego en sus posibilidades como objeto de comprensión.

\section{Bibliografía}

Boeri, M. (2007), "Filosofía y Drama en el Teeteto de Platón”, en J. M. Zamora, A. Correa (eds.), Diálogo y Filosofía (Homenaje a María Isabel Santa Cruz en su $65^{\circ}$ aniversario). Madrid-Bogotá: Universidad Autónoma de Madrid-Universidad Nacional de Colombia.

Fernández-Arancibia, J. (2007), "Gadamer und die platonische Philosophie", en Méthexis. Academia Verlag, Sankt Augustin, XX.

Gadamer, H. G., $(G W)$, Gesammelte Werke. Tübingen: J. C. B. Mohr (Paul Siebeck), 1986-1995.

(WMI), H. G., Wahrheit und Methode: Grundzüge einer philosophischen Hermeneutik. Tübingen: J. C. B. Mohr (Paul Siebeck), 1990. (1ª ed. 1960) 
(sigo en las citas la versión española de Verdad y método I. Fundamentos de una hermenéutica filosófica (traducción de Ana Agud Aparicio y Rafael de Agapito). Ediciones Sígueme, Salamanca 2003 (=1977).

(WM II), Wahrheit und Methode. Ergänzungen-Register, J. C. B. Mohr (Paul Siebeck), Tübingen 1993 (=1986). Citado según la versión española de Verdad y método II (traducción de Manuel Olasagasti). Salamanca: Ediciones Sígueme, 2006 (1 $1^{\mathrm{a}}$ ed. 1986).

(1931), Platos dialektische Ethik: Phänomenologische Interpretationen zum Philebos. Meiner, Hamburg 2000.

(1953), "Wahrheit in den Geisteswissenschaften", en WM II. (1957), "Was ist Wahrheit?”, en WM II.

(1965), "Hermeneutik und Historicismus", en WM II.

(1968), "Klassische und philosophische Hermeneutik", en WM II.

(1970), "Begriffsgeschichte als Philosophie", en WM II.

(1972), "Logos und Ergon im platonischen Lysis", en Griechische Philosophie II. GW VI, Tübingen 1985.

(1978), "Die Idee des Guten zwischen Platon und Aristoteles", en Griechische Philosophie III. Plato im Dialog. GW VII. Tübingen 1991.

(1983), "Text und Interpretation" en WM II.

(1985), “Sokrates' Frömmigkeit des Nichtweissens”, en Griechische Philosophie III. Plato im Dialog. GW VII. Tübingen 1991.

(1991), "Dialektik ist nicht Sophistik. Theätet lernt das im Sophistes", en Griechische Philosophie III. Plato im Dialog. GW VII. Tübingen 1991.

Heidegger, M. (SZ), Sein und Zeit. Tübingen: Max Niemeyer Verlag, 1972 (1 ${ }^{\text {a }}$ ed.: 1927). Citado según la versión española de Ser y Tiempo (traducción, prólogo y notas de J. E. Rivera C.). Santiago de Chile: Ed. Universitaria, $2002\left(1^{\mathrm{a}} \mathrm{ed}\right.$. 1997).

Natorp P. (1921), Platos Ideenlehre. Eine Einfuhrung in den Idealismus. Leipzig: Meiner.

Vigo, A. (2001), "Platón, en torno a las condiciones y la función del diálogo cooperativo". Tópicos (Revista de Filosofía de Santa Fe) 8/9: 5-41.

(2005). "Caridad, sospecha y verdad. La idea de la racionalidad en la hermenéutica filosófica contemporánea". Teología y Vida 46: 254-277.

Wieland, W. (1982). Platon und die Formen des Wissens. Göttingen: Vandenhoeck \& Ruprecht. 